\title{
Академгородок 2.0
}

\author{
В.К. Шумный凶
}

Аннотация: В статье рассмотрены основные направления реализации проекта Академгородок 2.0. Это прежде всего активное участие в нем молодых ученых и условия для этого. Усиление компонентов на стыках разных наук, создание современной инфраструктурыдля фундаментальных исследований. Проект Академгородок 2.0 является основополагающим для дальнейшего развития Сибирского отделения Российской академии наук, и необходимо сделать все, чтобы он был успешно реализован. Ключевые слова: Сибирское отделение Российской академии наук; Академгородок 2.0.

Для цитирования: Шумный В.К. Академгородок 2.0. Письма в Вавиловский журнал генетики и селекции. 2020;6(1):37-39. DOI 10.18699/Letters2020-6-05

\section{Akademgorodok 2.0}

V.K. Shumny $\bowtie$

Abstract: The article discusses the main areas of implementation of the project Akademgorodok 2.0. Primarily, these are the active participation of young scientists, setting up good conditions for this to happen, the perfection of interface elements between different sciences, and the creation of a modern infrastructure for basic research. Akademgorodok 2.0 is fundamental to a further development of the Siberian Branch, and so it is important to do everything in our power to make it real.

Key words: Siberian Branch of the Russian Academy of Sciences; Akademgorodok 2.0.

For citation: Shumny V.K. Akademgorodok 2.0. Pisma v Vavilovskii Zhurnal Genetiki i Selektsii = Letters to Vavilov Journal of Genetics and Breeding. 2020;6(1):37-39. DOI 10.18699/Letters2020-6-05 (in Russian)

Проект Академгородок 2.0 - это второе дыхание для Сибирского отделения Российской академии наук (СО РАН) за 60 лет его существования. Сибирское отделение РАН его заслужило. В деятельности СО РАН все было продумано основателями: фундаментальная наука, образование и связь с производством.

Сибирское отделение составляет существенную и эффективную часть Российской академии наук и уважаемую часть мирового научного сообщества. И это не преувеличение, а реальность. Даже в самые трудные времена оно не прекращало полноценно работать. Сутью своего существования оно обречено на это.

Дом - семья и дом - Институт - за 60 лет стало явью и смыслом для многих поколений новосибирского Академгородка. Проезжая поздно вечером по Академгородку, можно заметить у многих институтов светящиеся окна. Это значит, что идут долговременные эксперименты, которые нельзя прерывать ни днем ни ночью.

Всегда в почете был спорт, особенно зимой лыжный, и театрально-концертные программы в Доме ученых. Популяцию Академгородка, его научную элиту формировали веду- щие университеты страны. На первых порах это Московский и Ленинградский университеты, Физтех и другие. Но вскоре первое место в подготовке кадров для Академгородка занял Новосибирский государственный университет (НГУ). На примере Института цитологии и генетики СО РАН могу подтвердить, что сегодня более 60 \% его научных сотрудников составляют выпускники Новосибирского государственного университета. Михаил Алексеевич Лаврентьев, создавая университет и физико-математическую школу, многое взял из опыта создания Физтеха, в котором он принимал участие.

В чем смысл проекта Академгородок 2.0? Развитие науки всегда связано со сменой поколений и возрастающей доли молодых ученых, наиболее активных и амбициозных. И это поколение желает максимально эффективно реализовать свой потенциал в максимально благоприятных условиях для работы. Для этого необходима современная инфраструктура, приборная и реактивная база, достойная оплата труда и условия жизни, минимальная бюрократическая надстройка. Любой результат, даже гениальное открытие можно понятно изложить на одной странице и в нескольких научных статьях. В сотнях страниц отчета размывается 


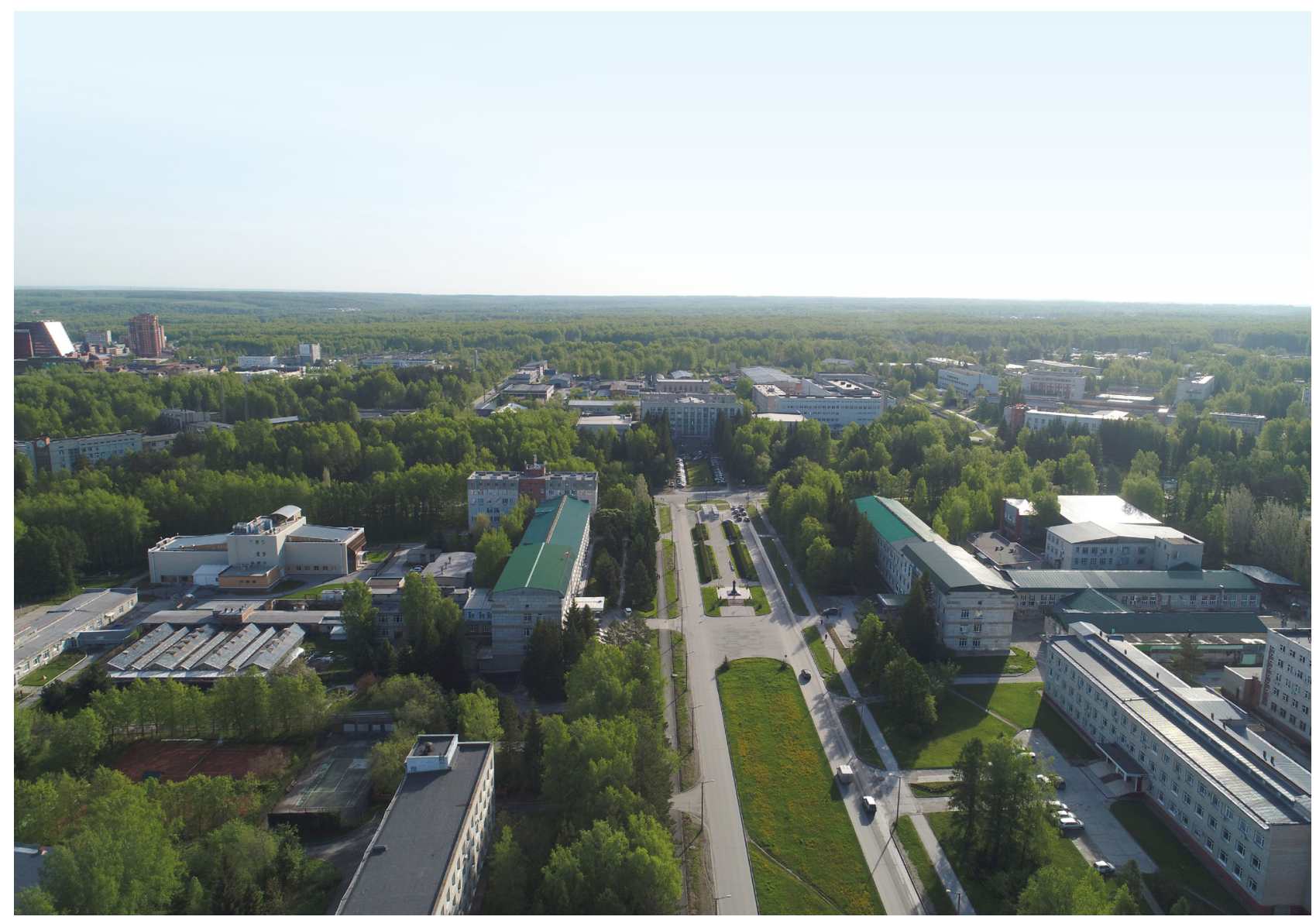

Академгородок, проспект Академика Коптюга Akademgorodok, Academician Koptyug Avenue

рациональное зерно, и есть подозрение, что вряд ли их ктото до конца читает. В данном случае полное несоответствие тому, что количество переходит в качество.

Нынешняя молодежь более прагматична, и она не будет десятилетиями ждать, когда что-то улучшится, а просто уедет в зарубежные лаборатории или уйдет из науки в бизнес или другие структуры. А это уже серьезный вызов стратегии нашего развития. Сейчас научно-техническое обеспечение экономики крайне необходимо. Конкурентоспособность может обеспечить сегодня только высокий научно-технический уровень страны. Повышение этого уровня до мировых стандартов, а лучше выше, не должно исходить только из повеления высшего начальства, а стать необходимой нормой жизни всего общества. В этом случае все придет в соответствии с реальностью.

Михаил Алексеевич Лаврентьев, создавая Сибирское отделение Академии наук СССР и академгородки, предполагал развитие очень мощной интеграционной компоненты и появление на стыках наук новых идей, а, следовательно, и открытий. И не ошибся в этом. Интеграция наук открывает также новые и мощные возможности для исследований. Проект Академгородок 2.0 при его реализации значительно усилит интеграционный потенциал.

Популяция жителей Академгородка формировалась поособому. Была поставлена задача создать условия для мак- симального общения представителей разных наук, в том числе и в нерабочее время. Я старожил Сибирского отделения. Академгородку уже 61 год. Мое поколение с любовью и в шутку называло Академгородок «большая деревня Лаврентьевка». И, как водится, в деревне почти все знают друг друга. Так было в первые десятилетия.

Сейчас в структуре населения Академгородка существенно увеличилось количество жителей, не работающих В институтах СО РАН. Сменилось несколько поколений. Нам на смену пришли молодые и активные выпускники НГУ. Несомненно, что будущее сибирской науки, да и СО РАН зависит от них. И возникает сложная трудно решаемая проблема их благоустройства и прежде всего обеспечение жильем. Уверен, что в проекте Академгородок 2.0 решение этой проблемы должно быть первостепенной задачей, так как от нее многое зависит.

Размышляя над развитием СО РАН, нужно всегда особое значение придавать научным кадрам, особенно последующим поколениям. Следует бережно сохранять и активно использовать преемственность поколений. Старшие поколения Сибирского отделения РАН обладают огромным опытом организации и развития научных исследований. Именно они принесли мировую известность Академгородку и всему Сибирскому отделению. Серьезным вызовом для российской науки, в том числе и для Сибирского отделения 
стал отъезд молодых и перспективных ученых в зарубежные лаборатории. Это началось в конце 1980-х и приобрело массовый характер в 1990-е годы. Поводов для отъезда за рубеж было достаточно. Резко ухудшились условия для работы ученых в своей стране. В 1990-е годы финансирование науки уменьшилось в несколько раз. Для науки настали тяжелые времена. Престиж ученого начал резко падать. Это и обусловило массовый отъезд за рубеж. К сожалению, хотя и в меньшей степени, он продолжается и сегодня. Выполнение проекта Академгородок 2.0 должно учитывать этот чрезвычайно важный момент и свести утечку кадров за рубеж к минимуму. А это возможно только при существенном улучшении условий работы и жизни.

В Советском Союзе поощрялись как фундаментальные, так и прикладные исследования. Результаты фундаментальных исследований публиковали в научных журналах, в основном отечественных, и оценивали по интересам коллег к ним, по цитированию, за которым следили сами авторы статей.

Только формальными критериями оценки публикаций не пользовались по причине их субъективности. Два примера. Грегор Мендель в малотиражном журнале опубликовал работу «Опыты над растительными гибридами», в которой постулировал открытие материальных наследственных факторов, позже названных генами. Но никто из прочитавших эту работу не понял. Только спустя более 30 лет ее нашли повторно. Один дотошный немец-ботаник написал книгу о гибридизации у растений и сослался на работу Г. Менделя. По этой ссылке и нашли статью повторно и поняли, что именно Г. Мендель открыл гены и стал основателем новой науки генетики. Но он не дожил до своего триумфа.

Другой пример. Датский биохимик Йохан Кьельдаль опубликовал статью о методе определения белка. Ботаники, генетики, селекционеры сразу начали активно использовать этот метод, естественно, ссылаясь на работу Й. Кьельдаля. И он мгновенно стал для биологов самым цитируемым автором. Именно поэтому я назвал формальные критерии оценки публикаций субъективными.

В советское время весьма значимо оценивали практические разработки. Для примера. Генетики и селекционеры создавали более продуктивные сорта растений, породы животных и штаммы микроорганизмов. Их оценку проводили по объемам внедрения: сорта по занимаемым площадям в гектарах, породы по количеству животных, штаммы по объемам ценных компонентов. Объемы внедрения поощряли материально и приравнивали к рейтинговым показателям. Это стимулировало прикладные исследования, что крайне важно для развития новых технологий во всех сферах производства. Казалось бы, что объединение трех академий: РАН, сельскохозяйственной и медицинской - усилит внедренческую компоненту фундаментальной науки, но это пока не реализовалось. Одна из причин этого - оценка научной деятельности объединенных академий только по публикациям в рейтинговых, в первую очередь зарубежных журналах. Но такая оценка определяет место ученого или коллектива в международном научном сообществе. И это правильно и почетно для ученых, фундаменталистов и теоретиков, умеющих обобщать накопленные знания.

Практическое использование научных результатов касается прежде всего страны, где работает ученый, в нашем случае России. Если внедрение получает высокую оценку в своей стране, то оно получает шанс выйти и на международный уровень. Несомненно, результаты прикладных и фундаментальных исследований должны быть оценены не только по публикациям. Для прикладных изысканий очень важны объемы и результаты их внедрения. И, чтобы поощрять связь науки с производством, что очень важно, необходимо вводить новые критерии оценки этой деятельности.

Важнейший вопрос - управление наукой. Российская академия наук создана Петром Первым и успешно функционирует уже почти триста лет. Именно Академия обеспечивала фундаментальные исследования в России по всем направлениям наук. За три столетия Академия совершенствовала свою структуру и систему управления научным процессом в России.

В Советском Союзе высшим органом управления Академией было общее собрание ее членов. Оно избирало членов Академии, ее устав и исполнительное звено - Президента и Президиум Академии. Основной задачей Академии было развитие фундаментальных исследований. Главными структурными единицами Академии были научно-исследовательские институты по всем направлениям наук. В составе Правительства был Госкомитет по науке и технике, который формировал научно-техническую политику страны и активно поддерживал прикладные исследования.

Реформа Российской академии наук началась в 2012 году. Было организовано Федеральное агентство научных организаций (ФАНО), которому были переданы все Институты РАН. В 2018 году ФАНО преобразовано в Министерство науки и высшего образования. Теперь финансирование институтов и управление имуществом Академии осуществляет Министерство. Академия наук сегодня превратилась в экспертное сообщество. «Идея двух ключей» для взаимодействия Академии и ФАНО, а теперь Министерства науки и образования в полной мере так и не реализована. Несомненно, что система управления наукой требует улучшения. Успокаивает то, что институты, несмотря на смену подчиненности, работают в том же режиме, что и раньше.

Чрезвычайно важно, что для выполнения проекта Академгородок 2.0 должна быть разработана четкая система управления процессом, его реализации. Экономический прорыв России, который заложил в своей программе В.В. Путин, возможен только при наращивании и существенной поддержке фундаментальных исследований и инженерно-технологических проектов. И в этом русле Академгородок 2.0 является существенной частью развития экономики Сибири, а, значит, и всей России. 